\title{
Antitumor effect of a pyrazolone-based-complex [Cu(PMPP-SAL)(EtOH)] against murine melanoma B16 cell in vitro and in vivo
}

\author{
AYIPAIRI ABULA ${ }^{1}$ \\ JING ZHAO ${ }^{1,2}$ \\ GUANCHENG XU \\ YIJIE LI ${ }^{1}$ \\ SURONG SUN ${ }^{1, *}$ \\ ${ }^{1}$ Xinjiang Key Laboratory of Biological \\ Resources and Genetic Engineering \\ College of Life Science and Technology \\ Xinjiang University, Urumqi 830046 \\ PR China

\section{${ }^{2}$ People's Hospital of Xinjiang Uygur Autonomous Region, Urumqi 830046 PR China \\ ${ }^{3}$ Institute of Applied Chemistry Xinjiang University, Urumqi 830046 PR China}

\begin{abstract}
Pyrazolone-based derivative metal complexes were reported to have cytotoxicity in some tumor cells. In this study, the antitumor effect of [Cu(PMPP-SAL)(EtOH)] (PMPP-SAL $=N$-(1-phenyl-3-methyl-4-propenylidene-5-pyrazolone)salicylidene hydrazide anion) in murine melanoma B16 cells in vitro and in vivo was investigated. The results showed that $[\mathrm{Cu}(\mathrm{PMPP}-\mathrm{SAL})(\mathrm{EtOH})]$ inhibited the survival of B16 cells in vitro, and the $I C_{50}$ value was superior to cisplatin (DDP) $(p<0.001)$. B16 cell apoptosis was significantly higher in comparison to the control group (DMSO) $(p<0.01)$, and cell cycle arrest occurred at the G0/G1 phase. When challenged C57 BL/6J mice were treated with [Cu(PMPP$\mathrm{SAL})(\mathrm{EtOH})]$, a smaller volume of B16 solid tumors were reported than the control group $(p<0.01)$, with lower positive expression indices of CD 34, vascular endothelial growth factor (VEGF) and basic fibroblast growth factor (bFGF) $(p<0.01)$. Moreover, the tumor growth was suppressed in mice due to the induction of apoptosis, as detected by the TUNEL assay $(p<0.001)$. In summary, [Cu(PMPP-SAL)(EtOH)] effectively inhibited the growth of B16 cells in vitro and in vivo due to the induction of apoptosis and the inhibition of intra-tumoral angiogenesis, demonstrating its therapeutic potential in melanoma treatment.
\end{abstract}

Keywords: malignant melanoma, [Cu(PMPP-SAL)(EtOH)], apoptosis, tumor microangiogenesis
Accepted February 10, 2020

Published online April 10, 2020 
acquired resistance $(5,6)$. In addition, due to the strong drug resistance observed in melanoma cells (7), there is an urgent need to develop more effective anti-melanoma drugs.

Non-platinum metal-containing chemotherapeutic drugs have been characterized by high activity, low toxicity, and good antitumor effects (8-10). Recent studies have shown that the complexes formed by double Schiff's bases and copper are capable of inhibiting tumor growth and prolonging the survival time of tumor-bearing animals, eliminating the toxic side effects and drug resistance observed with traditional drugs such as DDP (11, 12 , 14). Pyrazolone complexes, within the category of double Schiff base complexes, can form several types of complexes by reacting with different metals. Notably, pyrazolonebased metal complexes possess the advantages of simple synthesis, stable properties, easy structural modification, and obvious antitumor effects (8-10) and are expected to develop as a new type of anticancer drugs.

Recent studies have implied that the pyrazolone-based derivative complex [Cu(L1) $(\mu-\mathrm{Cl})] \mathrm{Cl}(\mathrm{L} 1=3$-methyl-5-oxo-1-phenyl-3-pyrazoline-4-carboxaldehyde) had a significantly lower $I C_{50}$ value in melanoma B16 cells than DDP. In addition, this complex displayed significant cytotoxicity in B16 cells compared to DDP (12). Some studies suggest that the pyrazolone copper complex $\left[\mathrm{Cu}\left(\mathrm{R}-\mathrm{L}^{2}\right)_{2}\right] \cdot$ EtOAc and $\left[\mathrm{Cu}\left(\mathrm{S}-\mathrm{L}^{2}\right)_{2}\right] \cdot$ EtOAc $\left(\mathrm{R} / \mathrm{S}-\mathrm{HL}^{2}=(\mathrm{R} / \mathrm{S})-(1-\right.$ naththyl)-3-methoxysalicylaldimine, EtOAc = ethyl acetate)) had demonstrated obvious cytotoxic effects on breast cancer MDA-MB-231 cells, lung cancer A549 cells, and cervical cancer HeLa cells. Furthermore, the above complexes induce apoptosis and necrosis in MDA-MB-231 cells (13). However, there are limited reports available on the antitumor effects of the pyrazolone-based derivative copper complex in melanoma.

Previously, cytotoxicity and cell apoptosis induced by pyrazolone-based derivative copper complex Lgf-YL-9 ([Cu(PMPP-SAL)(EtOH)] (PMPP-SAL = 1-phenyl-3-methyl-4-propionyl-5-pyrazolone and salicylic hydrazide)) on human mouth floor cancer KB cells and multidrug-resistant KBV200 cells were investigated. The results indicated potent cytotoxicity against KB and KBV200 cells and induced cell apoptosis (14). Meanwhile, our previous study on the acute toxicity of [Cu(PMPP-SAL)(EtOH)] showed that $[\mathrm{Cu}(\mathrm{PMPP}-\mathrm{SAL})$ $(\mathrm{EtOH})]$ at low concentration had mild toxicity in mice, with lower acute toxicity than DDP (15). In this study, we have examined the anti-proliferative effect of [Cu(PMPP-SAL)(EtOH)] in murine melanoma B16 cells, and the in vivo effect on angiogenesis in B16 solid tumor. The results of the present study would provide insight into the application of pyrazolonebased derivatives in the treatment of melanoma.

\section{EXPERIMENTAL}

\section{Materials}

3-(4,5-Dimetrylthiazol-2-yl)-2,5-diphenyltetrazolium bromide (MTT, Sigma, USA). Apoptosis detection kit and cell cycle kit were purchased from Lianke. Dimethyl sulfoxide (DMSO, Sigma), Hoechst 33258. Other routine laboratory reagents were obtained from commercial sources of analytical grade. Neofuge 13R High-Speed Centrifuge (Heal Force, Hong Kong, China). Benchmark plus Microplate Reader (Bio-Rad, USA). XD-101 Invert Microscope (Jiangnan Brand) (Wuhan Oka Technology Co., Ltd.). 3423 Type CO2 incubator (Themo Corporation, USA). Flow Cytometry (US BD). In situ cell apoptosis detection kit was purchased from Wuhan Boster Biological Technology, China. 


\section{Complex and animals}

The pyrazolone-based derivative copper complex [Cu(PMPP-SAL)(EtOH)] was prepared and characterized with the purity of $>95 \%$ by the Institute of Applied Chemistry, Xinjiang University (Fig. 1) (16). C57BL/6J female mice (18-22 g) were purchased from the Laboratory Animal Center of Xinjiang Medical University. The animal experimental protocol was approved by the Animal Ethics Committee of Xinjiang University (license number: SCXK (new) 2016-0003).

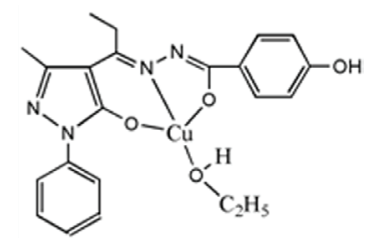

Fig. 1. Chemical structure of [Cu(PMPP-SAL)(EtOH)].

\section{Cell lines and culture}

The murine melanoma cell lines (B16) and non-tumor rat Schwann (RSC) cells were obtained from the Xinjiang Key Laboratory of Biological Resources and Genetic Engineering. The cells were cultured in RPMI 1640 medium (HyClone, Thermo) containing $10 \%$ fetal bovine serum (FBS, Gibco) and $1 \%$ penicillin-streptomycin $\left(100 \mathrm{U} \mathrm{mL}^{-1}\right.$ penicillin and $100 \mu \mathrm{g} \mathrm{mL} \mathrm{m}^{-1}$ streptomycin) under humidified $5 \% \mathrm{CO}_{2}$ (3423 Type $\mathrm{CO}_{2}$ incubator, Thermo Corporation, USA) atmosphere at $37^{\circ} \mathrm{C}$ as previously described (17).

\section{Cell viability assay}

B16 and RSC cells were seeded in 96-well plates at densities of $5 \times 10^{4}$ and $2.5 \times 10^{4}$ cells, respectively. After $24 \mathrm{~h}$ of incubation, the cells were treated with various concentrations of [Cu(PMPP-SAL)(EtOH)] (1, 5, 10, $\left.15 \mu \mathrm{mol} \mathrm{L}^{-1}\right)$ and the control, dimethyl sulfoxide (DMSO) (Sigma, USA) (0.1\% in culture media). After 24,48 and $72 \mathrm{~h}$ of treatments, $20 \mu \mathrm{L}$ of MTT (Sigma, USA) $\left(10 \mu \mathrm{mol} \mathrm{L}{ }^{-1}\right.$ MTT in phosphate-buffered saline (PBS) was added and cells were incubated for a further $4 \mathrm{~h}$. The supernatant was removed and MTT crystals were dissolved using $100 \mu \mathrm{L}$ of anhydrous DMSO in each well. Next, the absorbance was read at 570/655 nm using the Benchmark plus Microplate Reader (Bio-Rad, USA). The percentage of cell growth inhibition was calculated using the Eqation 1:

$$
\text { Cell growth inhibition }(\%)=(1-\text { mean exp. abs./mean control abs. }) \times 100 \%
$$

The $I C_{50}$ value was determined. All experiments were repeated at least three times.

\section{Wound healing assay}

The cells were plated at $5 \times 10^{4}$ cells with $2 \mathrm{~mL}$ per well in 6-well plates, and cultured to full confluence, with monolayers forming overnight after incubation. Next, a $10 \mu \mathrm{L}$ sterile pipette tip was used to create a straight wound in each cell layer. Next, the cells were washed three times with PBS and incubated with different concentrations of [Cu(PMPP-SAL)(EtOH)] 
$(5,10,15 \mathrm{M})$ in serum-free medium for $24 \mathrm{~h}$. The gap created by the scratch was observed at 0, 12, $24 \mathrm{~h}$ of incubation and photographed under XD-101 Invert Microscope (Jiangnan, China) at $200 \times$ magnification.

\section{Cell colony-forming assay}

The cells were plated at $1 \times 10^{3}$ cells with $2 \mathrm{~mL}$ per well in 6-well plates. After overnight incubation, the cells were treated with various concentrations of [Cu(PMPP-SAL)(EtOH)] $(5,10,15 \mathrm{M})$ for $24 \mathrm{~h}$, and washed with ice-cold PBS three times, and then cultured in $10 \%$ 1640 medium for $4 \mathrm{~d}$. After more than 20 colonies being formed, the cells were fixed with $1 \mathrm{~mL}$ of $4 \%$ paraformaldehyde solution for $20 \mathrm{~min}$ and then stained with $0.1 \%$ crystal violet solution (95\% anhydrous ethanol + $5 \%$ PBS) for 15-20 min.

\section{Hoechst 33258 staining}

A sterile clean coverslip was placed in 6-well plates and B16 cells were seeded at a density of $5 \times 10^{4}$ cells with $2 \mathrm{~mL}$ per well. After treatment with various concentrations of [Cu(PMPP-SAL)(EtOH)] (5, 10, 15M), B16 cells were washed with ice-cold PBS twice and stained with $1 \mathrm{~mL}$ Hoechst 33258 (Sigma, USA) in the dark at $37^{\circ} \mathrm{C}$ for $5 \mathrm{~min}$ (final concentration, $\left.0.5 \mu \mathrm{g} \mathrm{mL}^{-1}\right)$. After washing with PBS, the cells were observed using fluorescence microscopy (Leica Dmirb, Germany) in random microscopic fields at $400 \times$ magnification (18).

\section{Cell cycle assay}

B16 cells were seeded in 6-well plates at $5 \times 10^{4}$ cells with $2 \mathrm{~mL}$ per well, treated with different concentrations of [Cu(PMPP-SAL) $(\mathrm{EtOH})](5,10,15 \mathrm{M})$ and DMSO (control), and then incubated for $24 \mathrm{~h}$ and $36 \mathrm{~h}$ at $37^{\circ} \mathrm{C} / 5 \% \mathrm{CO}_{2}$ in humidified atmosphere. The cells then were collected by centrifugation at $1000 \times \mathrm{g}$ for $2 \mathrm{~min}$ (Neofuge 13R High-Speed Centrifuge, Heal Force, Hong Kong, China). Next, the cells were fixed by the dropwise addition of an equivalent volume of cold $70 \%$ ethanol after washed twice with cold PBS. The samples were stored at $-20{ }^{\circ} \mathrm{C}$. The cells were pelleted and then resuspended in propidium iodide/RNase PBS solution and analyzed using the FACS Calibur flow cytometer (US, BD).

\section{Annexin V/PI double staining assay}

Cell apoptosis was detected by annexin V staining. Briefly, B16 cells were treated with $[\mathrm{Cu}(\mathrm{PMPP}-\mathrm{SAL})(\mathrm{EtOH})]\left(5,10,15 \mathrm{~mol} \mathrm{~L}^{-1}\right)$ and washed twice with PBS. Next, the cells were then suspended in $400 \mu \mathrm{L}$ Binding buffer and treated with annexin V and propidium iodide (PI) staining. After 24 and $36 \mathrm{~h}$ of incubation, the cells were sorted and analyzed by flow cytometry.

\section{Establishment of the tumor-bearing model in mice}

B16 cells were suspended in normal saline at a density of $1 \times 10^{6}$ cells and implanted in C57BL/6J mice (6 weeks old) for chemotherapeutic studies. The mice were treated subcutaneously with $2 \times 10^{5}$ cells under the right hind leg (dorsum). Twenty-four hours after 
inoculation, the animals were randomized into 5 groups ( 7 mice per group) including control (DMSO, $10 \mu \mathrm{mol} \mathrm{L}^{-1}$ ), positive control group (DDP, $20 \mu \mathrm{mol} \mathrm{L}^{-1}$ ) and [Cu(PMPP$\mathrm{SAL})(\mathrm{EtOH})]\left(20,40,60 \mu \mathrm{mol} \mathrm{L}^{-1}\right)$.

\section{Effect of $[C u(P M P P-S A L)(E t O H)]$ on the B16 solid tumor growth}

Five days after injection, when the tumor reached $0.3 \times 0.3 \mathrm{~cm}$ in size, the drug was intratumorally injected at a volume of $100 \mu \mathrm{L}$ per mice for 8 days. The volume of the tumor was measured every 2 days with calipers, with the longest (a) and the shortest diameter (b) of the tumor were measured. Tumor volumes $(V)$ and relative tumor volume (RV) were calculated using the Equation 2.

$$
V=a \times b^{2} \times 0.5, \mathrm{RTV}=V / V_{0}
$$

where $V_{0}$ is the tumor volume before dosing and $V$ is the tumor volume after dosing (19). On the day after the drug was stopped, the mice were sacrificed. B16 tumors were excised and weighed.

\section{Immunohistochemical analysis}

Tumor tissues obtained from mice were fixed in $10 \%$ formaldehyde solution in phosphate buffer and routinely processed by paraffin embedding. The changes in the tissue were observed under light microscopy after hematoxylin-eosin (HE) staining. After dewaxing the tumor paraffin sections of each group of mice, the sections were incubated with rabbit anti-CD34, vascular endothelial growth factor (VEGF), and basic fibroblast growth factor (bFGF) $\mathrm{mAb}$ at $4{ }^{\circ} \mathrm{C}$ overnight, and color development carried out by immersion in $0.05 \%$ 3,3'-diamino-benzidine tetrahydrochloride (DAB) as chromogen for $5 \mathrm{~min}$. The distribution of CD 34, VEGF, and bFGF in the tumor was observed using microscopy. In accordance with the SV-0002 two-step immunohistochemistry kit manufacturer's instruction, the results of the brown and the intensity of the color were taken as an indicator of observation. First, the distribution of CD 34, VEGF or bFGF on the whole pathological tissue section was observed under a low power microscope (100×) and the most intensive 5 regions, "hot spots" of CD 34, VEGF and bFGF, were identified. The number of CD 34, VEGF, and bFGF in each spot was counted using a high power microscope (200*), and the average number of cells in the five hot spots is taken as the density of CD 34, VEGF or bFGF in the tumor of the mice.

\section{TUNEL apoptosis assay in vivo}

Apoptosis analysis was performed by TUNEL (terminal deoxynucleotide transferasemediated dUTP nick end-labeling) staining using an in situ cell apoptosis detection kit (Boster Biological Technology, Wuhan, Hubei, China) according to the manufacturer's instructions. The results of the bluish-violet were taken as an indicator of apoptotic cells. TUNEL-positive nuclei, a pyknotic nucleus with bluish-violet granules, were visualized and analyzed under a light microscope (200×). Cell numbers were counted in 5 random fields and apoptosis indexes (AI) were calculated as the ratio of the positive cell number to the total tumor cell number, based on the mean value from five high power fields via computer-assisted assay. 


\section{RESULTS AND DISCUSSION}

\section{Synthesis of the copper complex [Cu(PMPP-SAL)(EtOH)](16)}

The elemental analysis, single-crystal X-ray diffraction, and thermogravimetric analysis of $[\mathrm{Cu}(\mathrm{PMPP}-\mathrm{SAL})(\mathrm{EtOH})]$ were performed (16), the results indicated that the complex $[\mathrm{Cu}(\mathrm{PMPP}-\mathrm{SAL})(\mathrm{EtOH})]$ was a pure substance.

\section{$[C u(P M P P-S A L)(E t O H)]$ effectively inhibited the growth of B16 cells in vitro}

Melanoma is a type of skin tumor characterized by a high degree of malignancy, multiple occurrences and extremely low survival rate of patients. It has been well documented that this type of neoplasm presents a high metastatic rate, and is able to involve

a)

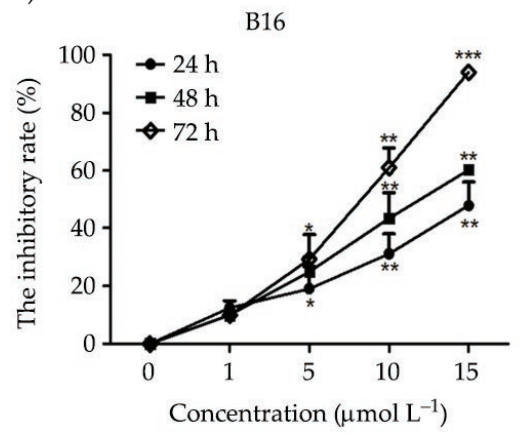

c)

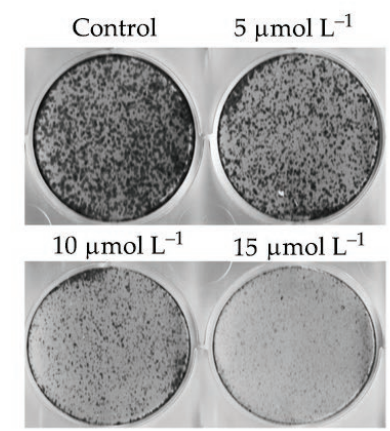

b)

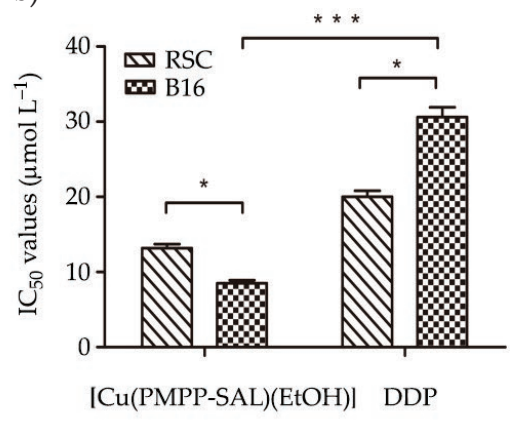

d)

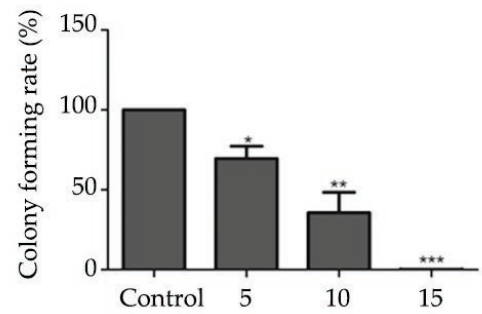

Concentration $\left(\mu \mathrm{mol} \mathrm{L}^{-1}\right)$

Fig. 2. The inhibitory effect of [Cu(PMPP-SAL)(EtOH)] on the proliferation of B16 cells: a) B16 cells were treated with indicated concentrations of [Cu(PMPP-SAL)(EtOH)] for 24, 48 and $72 \mathrm{~h}$, respectively, and cell viability was measured by MTT assay; b) $I C_{50}$ values of [Cu(PMPP-SAL) $\left.(\mathrm{EtOH})\right]$ and positive control group (DDP) in B16 and RSC cells after $72 \mathrm{~h}$ treatments. ${ }^{* * *} p<0.001$ vs. positive control group (DDP); c) the colony formation in B16 cells, B16 cells were treated with indicated concentrations of [Cu(PMPP$\mathrm{SAL})(\mathrm{EtOH})]$ for $24 \mathrm{~h}$, then incubated for $5 \mathrm{~d}$. Then the cells were fixed with methanol and stained with crystal violet. d) The corresponding cell healing rate was calculated. Data are presented as mean \pm SD $(n=3) .{ }^{*} p<0.05,{ }^{* *} p<0.01,{ }^{* * *} p<0.001$ vs. control group (DMSO, $0.1 \%$ in culture media). 
nearly every tissue (20). Currently, effective therapeutic methods for the treatment of melanoma remain poorly investigated. Therefore, the development of new treatment methods and drugs is of crucial medical significance for treating melanoma and improving the survival rate in patients.

Here, to assess the growth inhibition in B16 cells induced by [Cu(PMPP-SAL)(EtOH)] complex, the MTT assay was performed after 24, 48, $72 \mathrm{~h}$ of drug treatment. The results indicated that $[\mathrm{Cu}(\mathrm{PMPP}-\mathrm{SAL})(\mathrm{EtOH})]$ inhibited $\mathrm{B} 16$ cell proliferation in a concentrationand time-dependent manner (Fig. 2a). After $72 \mathrm{~h}$ drug treatment, the $I C_{50}$ value of [Cu(PMPP-SAL)(EtOH)] in B16 cells was $8.5 \mu \mathrm{mol} \mathrm{L}^{-1}$, which was markedly effective than $\operatorname{DDP}\left(I C_{50}: 30.1 \mu \mathrm{mol} \mathrm{L}^{-1}\right)$ in inhibiting B16 cell growth $(p<0.05)$. The $I C_{50}$ value of $[\mathrm{Cu}(\mathrm{PMPP}-$ $\mathrm{SAL})(\mathrm{EtOH})]$ for non-neoplastic RSC cells was similar to DDP (Fig. 2b). These results suggested that $[\mathrm{Cu}(\mathrm{PMPP}-\mathrm{SAL})(\mathrm{EtOH})]$ had a relatively strong cytotoxic profile in cancer cells compared to normal cells $(p<0.05)$.

To investigate the effect of [Cu(PMPP-SAL)(EtOH)] on colony formation in B16 cells, we examined the growth capacity of B16 cells at a very low density. The results indicated that $[\mathrm{Cu}(\mathrm{PMPP}-\mathrm{SAL})(\mathrm{EtOH})]$ had a significant toxic effect on the growth of B16 cells (Fig. 2c), inhibiting colony formation in B16 cells in a concentration-dependent manner (Fig. 2d). The cells in the treatment groups demonstrated a significant reduction in colony-forming efficiency compared to the blank control group, indicating that [Cu(PMPP-SAL)(EtOH)] inhibited the growth of B16 cells $(p<0.01)$.

\section{$[\mathrm{Cu}(\mathrm{PMPP}-\mathrm{SAL})(\mathrm{EtOH})]$ inhibited the migration of B16 cells}

Metastasis is one of the main features of malignant melanoma. To examine the effect of $[\mathrm{Cu}(\mathrm{PMPP}-\mathrm{SAL})(\mathrm{EtOH})]$ on B16 cell migration, we performed cell healing assays in vitro.

a)

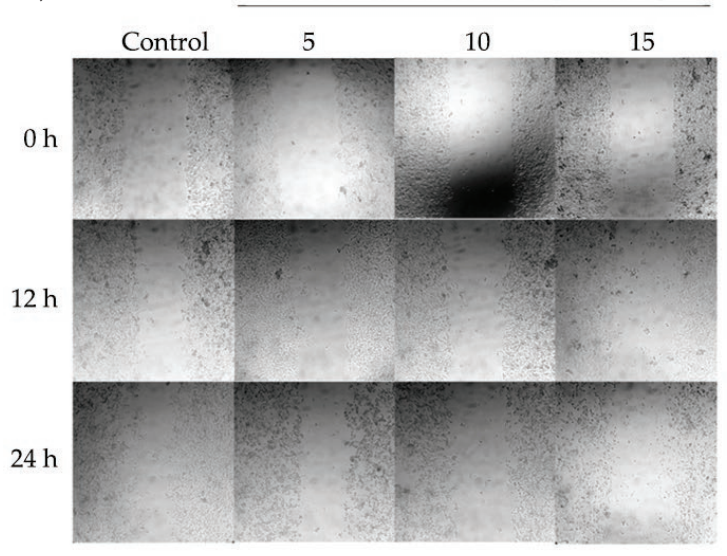

b)

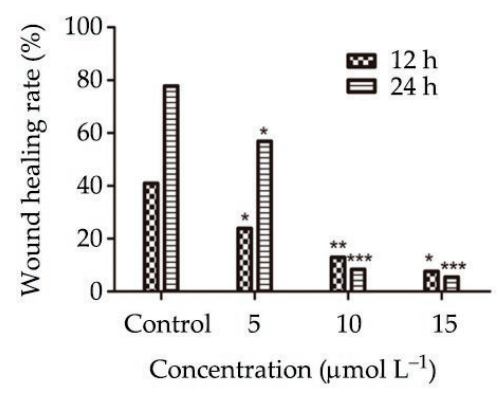

Fig. 3. Wound healing assay of B16 cells $24 \mathrm{~h}$ after treatment with [Cu(PMPP-SAL)(EtOH)]: a) B16 cells were treated with indicated concentrations of $[\mathrm{Cu}(\mathrm{PMPP}-\mathrm{SAL})(\mathrm{EtOH})]$ and migration was observed under a microscope at $200 \times$ magnification; b) the corresponding cell healing rates were calculated. ${ }^{*} p<0.05,{ }^{* *} p<0.01,{ }^{* * *} p<0.001$ vs. control group (DMSO, $0.1 \%$ in culture media). 
Cell migration was observed using an inverted microscope. The results demonstrated that the number of migrating [Cu(PMPP-SAL) $(\mathrm{EtOH})]$-treated cells was lower than that in the control group (Fig. 3a). Hence, [Cu(PMPP-SAL)(EtOH)] inhibited the migration of $\mathrm{B} 16$ cells in a concentration- and time-dependent manner. The cell wound healing rate at $24 \mathrm{~h}$ in the $15 \mu \mathrm{mol} \mathrm{L}-1$ treatment group was significantly lower (5.42 $\pm 0.22 \%)$ compared to the control group $(77.79 \pm 7.35 \%)(p<0.001)$ (Fig. $3 b)$.

\section{$[C u(P M P P-S A L)(E t O H)]$ affected the morphology of B16 cells}

The inhibition of cell growth in tumor cells is usually associated with increased apoptosis (21). To detect whether [Cu(PMPP-SAL)(EtOH)] can induce apoptosis in the tumor cells, B16 cells were stained by Hoechst 33258 with various concentrations of [Cu(PMPP-SAL) $(\mathrm{EtOH})]$ for $24 \mathrm{~h}$ and observed using inverted phase-contrast microscopy. As shown in Fig. 4, compared to the control group, the $15 \mu \mathrm{mol} \mathrm{L}^{-1}$ treated group revealed a reduction of adherent cell numbers and the presence of small and round cells, bright blue nuclei due to karyopyknosis and chromatin condensation (Fig. 4). The results indicated the existence of induced-apoptosis attributed to [Cu(PMPP-SAL)(EtOH)] treatment. Furthermore, cell death induced by $[\mathrm{Cu}(\mathrm{PMPP}-\mathrm{SAL})(\mathrm{EtOH})]$ might be associated with the induction of apoptosis.

\section{$[C u(P M P P-S A L)(E t O H)]$ arrested the cell cycle of B16 cells}

To detect the effect of [Cu(PMPP-SAL)(EtOH)] on cell cycle distribution, after treatment with different concentrations of [Cu(PMPP-SAL)(EtOH)] for $24 \mathrm{~h}$ and $36 \mathrm{~h}$, the cell cycle distribution of B16 cells was measured using flow cytometry. The rate of PI-stained positive cells in the G0/G1 phase was significantly increased after $24 \mathrm{~h}(63.11 \pm 1.02 \%)$ and $36 \mathrm{~h}(71.53 \pm 0.38 \%$ ) of treatment, respectively (Fig. 5, 4a). The results indicated that [Cu(PMPP$\mathrm{SAL})(\mathrm{EtOH})]$ arrested B16 cells at the G0/G1 phase of the cell cycle in a time- and dosedependent manner $(p<0.05)$ (Fig. 5b).

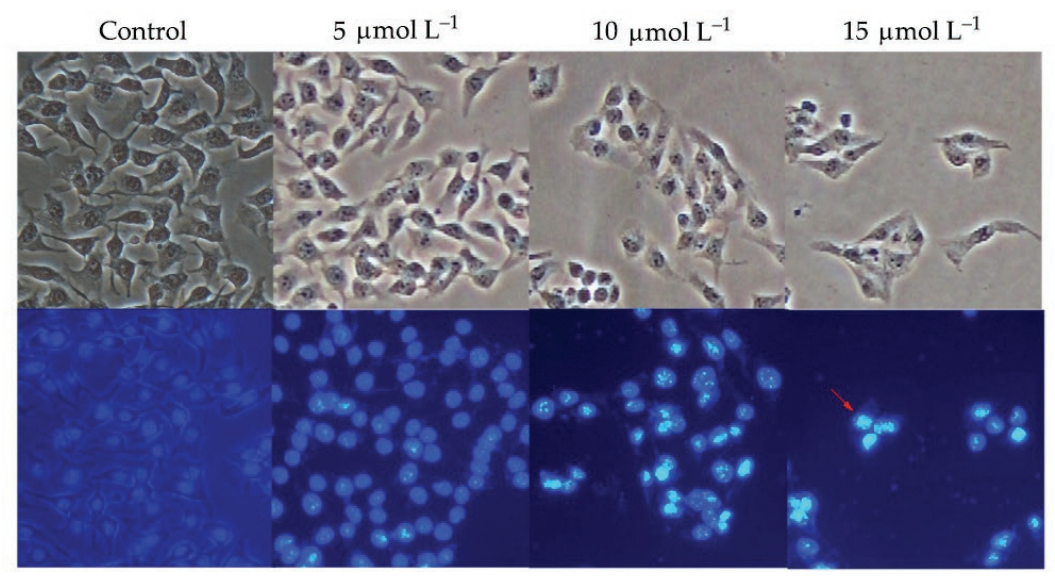

Fig. 4. B16 cell apoptosis induced by [Cu(PMPP-SAL)(EtOH)]. B16 cells were treated with various concentrations of [Cu(PMPP-SAL)(EtOH)] for $24 \mathrm{~h}$ and stained with Hoechst 33258 . Samples were observed under a fluorescent microscope at $400 \times$ magnification. The red arrow point to the apoptotic bodies. 
a) Control

$24 \mathrm{~h}$

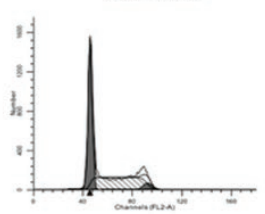

Control

$36 \mathrm{~h}$

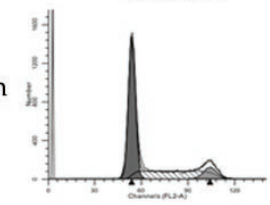

$5 \mu \mathrm{mol} \mathrm{L}^{-1}$

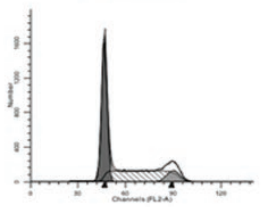

$5 \mu \mathrm{mol} \mathrm{L}^{-1}$

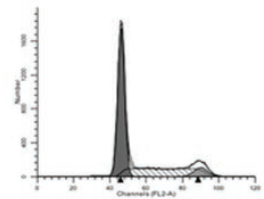

$10 \mu \mathrm{mol} \mathrm{L}^{-1}$

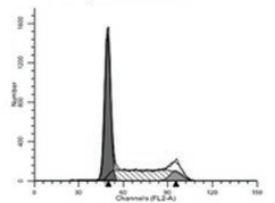

$10 \mu \mathrm{mol} \mathrm{L}^{-1}$

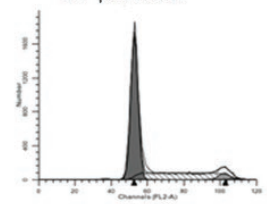

$15 \mu \mathrm{mol} \mathrm{L}^{-1}$

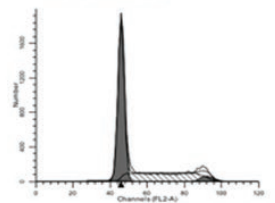

$15 \mu \mathrm{mol} \mathrm{L}^{-1}$

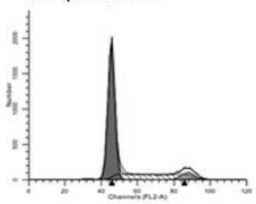

b)

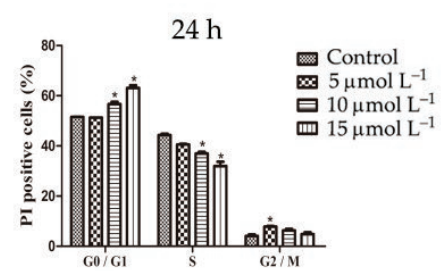

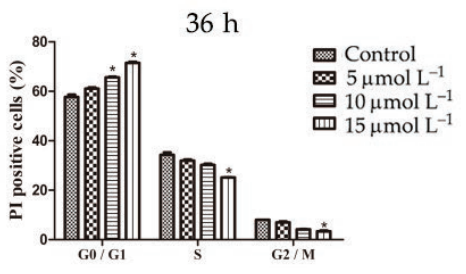

Fig. 5. Cell cycle changes in B16 cells after [Cu(PMPP-SAL)(EtOH)] treatment by flow cytometry: a) B16 cells were treated with indicated concentrations of [Cu(PMPP-SAL)(EtOH)] for $24 \mathrm{~h}, 36 \mathrm{~h}$, respectively; b) then subjected to cell cycle analysis after PI staining. Data are presented as mean $\pm \operatorname{SD}(n=3) .{ }^{*} p<0.05$ vs. control group (DMSO, $0.1 \%$ in culture media).

\section{$[C u(P M P P-S A L)(E t O H)]$ induced early apoptosis of B16 cells}

Annexin V/PI double staining is a sensitive method to detect apoptosis. To detect early apoptosis in $\mathrm{B} 16$ cells treated with [Cu(PMPP-SAL)(EtOH)], Annexin V/PI double staining was performed. As shown in Fig. 6a,b, after treatment for $24 \mathrm{~h}$ and $36 \mathrm{~h}$, the number of apoptotic cells treated with [Cu(PMPP-SAL)(EtOH)] increased remarkably in a timeand dose-dependent manner $(2.02 \pm 0.69 \%$ to $8.24 \pm 0.51 \%)$, and was significantly higher compared to the control group $(p<0.01)$ (Fig. 6b).

\section{$[\mathrm{Cu}(\mathrm{PMPP}-\mathrm{SAL})(\mathrm{EtOH})]$ effectively inhibited the growth of B16 cells in vivo}

Currently, there are limited reports on the in vivo antitumor activity of pyrazolone metal complexes. In the present study, C57 BL/6J treated with [Cu(PMPP-SAL)(EtOH)] demonstrated a significantly lower $\mathrm{RV}\left(V / V_{0}\right)$ in comparison to the control group $(p<0.01)$ (Fig. 7a, Table I). The relative curves of tumor growth and the tumor size are shown in Fig. 7.

In addition, the tumor inhibition rates were significantly increased after treatment with different concentrations of [Cu(PMPP-SAL)(EtOH)] $(p<0.01)$ (Table I), indicating that $[\mathrm{Cu}(\mathrm{PMPP}-\mathrm{SAL})(\mathrm{EtOH})]$ exerted a strong inhibitory effect on B16 solid tumor formation in C57 $\mathrm{BL} / 6 \mathrm{~J}$ mice. Notably, [Cu(PMPP-SAL)(EtOH)] did not cause any death or induce weight loss in 
a)
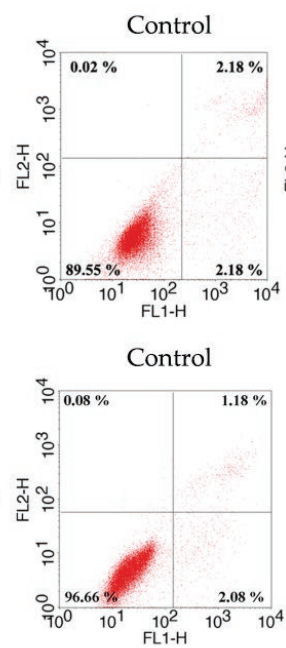

$5 \mu \mathrm{mol} \mathrm{L}^{-1}$

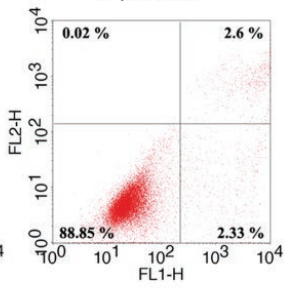

$5 \mu \mathrm{mol} \mathrm{L}^{-1}$

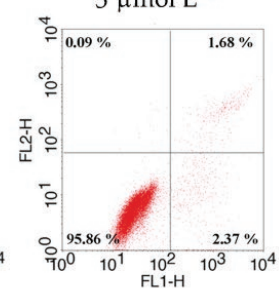

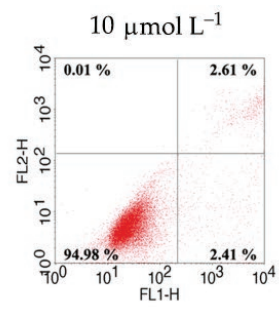
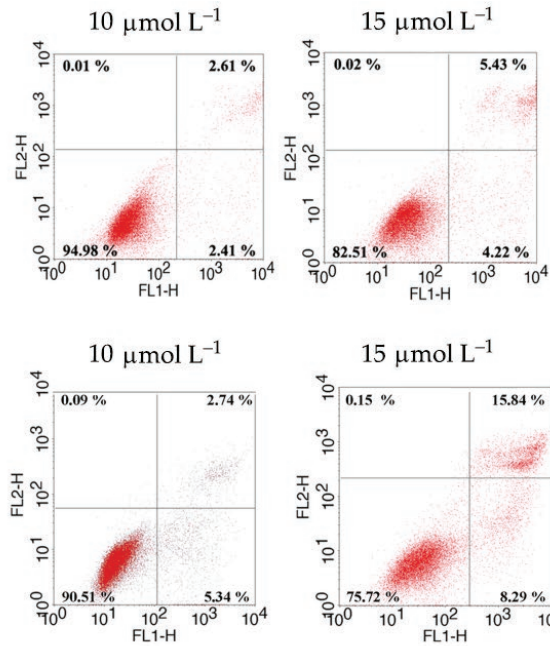

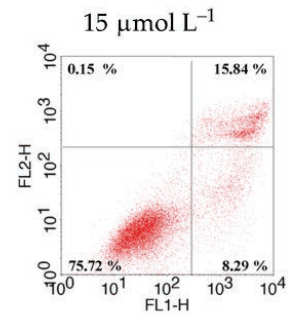

b)
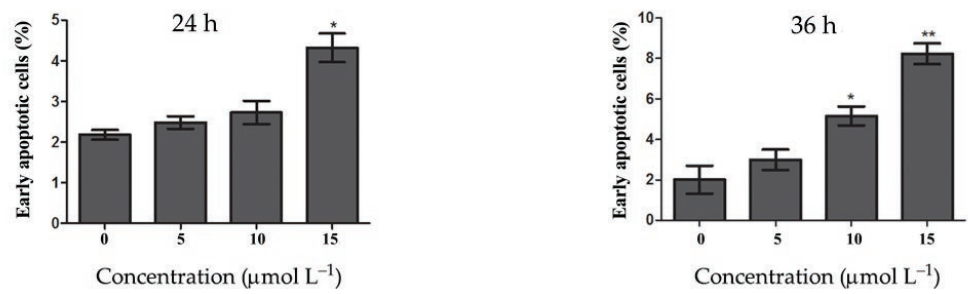

Fig. 6. Annexin V-FITC/PI staining detected apoptosis in B16 cells after treatment with [Cu(PMPP-SAL) (EtOH)] for $24 \mathrm{~h}, 36 \mathrm{~h}$ with indicated concentrations: a) B16 early apoptotic cells were analyzed by FACS Calibur flow cytometer; b) summary data (mean \pm SD) of early apoptotic cells are shown $(n=3) .{ }^{*} p<0.05$, ${ }^{* *} p<0.01$ vs. control group (DMSO, $0.1 \%$ in culture media).

Table I. Inhibitory effect of $[\mathrm{Cu}(\mathrm{PMPP}-\mathrm{SAL})(\mathrm{EtOH})]$ on B16 solid tumor growth in C57 BL/6J mice

\begin{tabular}{|c|c|c|c|c|}
\hline \multirow[b]{2}{*}{ Group } & \multicolumn{2}{|c|}{ Mice mass (g) } & \multirow{2}{*}{$\begin{array}{l}\text { Tumor } \\
\text { mass (g) }\end{array}$} & \multirow{2}{*}{$\begin{array}{c}\text { Inhibition } \\
\text { rate (\%) }\end{array}$} \\
\hline & $\begin{array}{l}\text { Pre-experi- } \\
\text { ment }\end{array}$ & $\begin{array}{l}\text { Post-experi- } \\
\text { ment }\end{array}$ & & \\
\hline $\begin{array}{l}\text { Negative control } \\
\qquad 10 \mu \mathrm{mol} \mathrm{L}^{-1}\end{array}$ & $19.50 \pm 0.97$ & $21.6 \pm 0.72$ & $1.30 \pm 0.26$ & 0.00 \\
\hline \multicolumn{5}{|c|}{ [Cu(PMPP-SAL)(EtOH)] } \\
\hline $20 \mu \mathrm{mol} \mathrm{L}{ }^{-1}$ & $17.88 \pm 0.94$ & $19.6 \pm 0.30$ & $0.84 \pm 0.39$ & $35.58 *$ \\
\hline $40 \mu \mathrm{mol} \mathrm{L}-1$ & $18.4 \pm 1.22$ & $18.9 \pm 1.51$ & $0.72 \pm 0.16$ & $44.44^{* *}$ \\
\hline $60 \mu \mathrm{mol} \mathrm{L}{ }^{-1}$ & $17.28 \pm 0.51$ & $17.75 \pm 0.86$ & $0.59 \pm 0.07$ & $54.8^{* *}$ \\
\hline $\begin{array}{l}\text { Cisplatin (DDP) } \\
20 \mu \mathrm{mol} \mathrm{L}^{-1}\end{array}$ & $18.49 \pm 0.84$ & $19.05 \pm 1.32$ & $0.73 \pm 0.09$ & $44.06^{* *}$ \\
\hline
\end{tabular}

$N=7 .{ }^{*} p<0.05,{ }^{* *} p<0.01,{ }^{* * *} p<0.001$ vs. control group (mean $\pm \mathrm{SD}$ ). 
a)

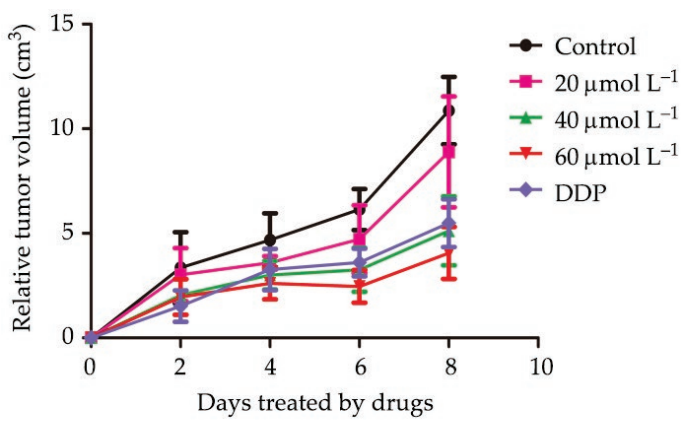

b)

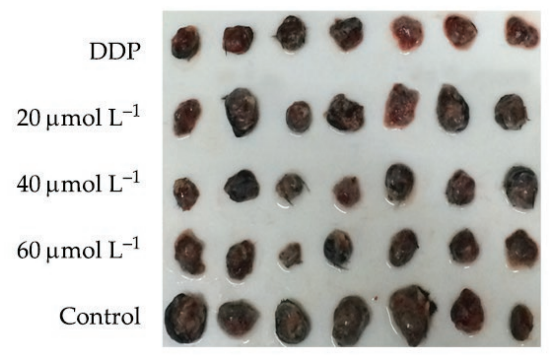

Fig. 7. Growth inhibition of B16 cells in C57BL/6J mice after [Cu(PMPP-SAL)(EtOH)] treatment. C57BL/6J mice were implanted subcutaneously (s.c.) with $2 \times 10^{5}$ cells under the right hind leg (dorsum). Animals were randomized into five groups including control (DMSO, $10 \mu \mathrm{mol} \mathrm{L}^{-1}$ ), positive control (DDP, $\left.20 \mu \mathrm{mol} \mathrm{L}^{-1}\right)$ and [Cu(PMPP-SAL)(EtOH)] group $\left(20,40,60 \mu \mathrm{mol} \mathrm{L}^{-1}\right)$. After injection for five days, when the tumor $0.3 \times 0.3 \mathrm{~cm}$ in size, the mice were injected intratumorally with the drug volume of $100 \mu \mathrm{L} /$ mouse for 8 days. The volume of the tumor was measured every 2 days; a) data are presented as means $\pm S D$ of the tumor volume for each group of 7 experimental animals; $b$ ) the picture presents the tumor size at the end of the experiment.

our experimental system (Table I). These data suggested that the toxicity of [Cu(PMPP-SAL) $(\mathrm{EtOH})]$ was tolerable. Therefore, we determined that [Cu(PMPP-SAL)(EtOH)] induced less damage in the melanoma-bearing mice, with lower toxic side effects. This is consistent with the acute toxicity of $[\mathrm{Cu}(\mathrm{PMPP}-\mathrm{SAL})(\mathrm{EtOH})]$ in mice as shown in the previous study (15).

\section{Tissue section and tumor immunohistochemistry analysis}

Researchers have proposed that the inhibition of the tumor angiogenesis might cause hypoxia in tumor cells and reduce the nutrient supply to tumor cells, eventually leading to tumor cell apoptosis and thus inhibiting tumor growth (22). The expression of VEGF and bFGF could affect the formation and growth of tumor blood vessels (23). Furthermore, newly generated blood vessels not only provide more nutrients to tumors but also increase the rate of tumor metastasis. Hence, microvessel density (MVD) is considered a gold standard for examining the invasion and metastatic potential of many primary tumors. Among the markers of vascular endothelial cells, CD34 has the highest sensitivity and hence the density of microvessels in tissues can be determined by detecting CD34 expression. CD34 promotes the proliferation of tumor vascular endothelial cells, as well as the interaction 
A. Abula et al:: E Antitumor effect of a pyrazolone-based complex [Cu(PMPP-SAL)(EtOH)] against murine melanoma B16 cell in vitro and in vivo, Acta Pharm. 70 (2020) 561-575.

Table II. Cell density expression of MVD, VEGF, bFGF in tumor tissues of C57 BL/6J mice

\begin{tabular}{cccc}
\hline Groups & MVD & VEGF & bFGF \\
\hline Negative Control & $113 \pm 19.56^{* * *}$ & $110 \pm 19.17^{* * *}$ & $109.2 \pm 20.59^{* * *}$ \\
$10 \mu \mathrm{mol} \mathrm{L}^{-1}$ & $57.4 \pm 8.20^{* *}$ & $56.4 \pm 7.57^{* *}$ & $58 \pm 5.39^{* *}$ \\
{$[\mathrm{Cu}(\mathrm{PMPP}-\mathrm{SAL})(\mathrm{EtOH})] 20 \mu \mathrm{mol} \mathrm{L}^{-1}$} & $33.2 \pm 7.79$ & $35.6 \pm 8.01$ & $37.5 \pm 5.46$ \\
$40 \mu \mathrm{mol} \mathrm{L}^{-1}$ & $22.8 \pm 4.92$ & $22.6 \pm 5.41$ & $22 \pm 2.35$ \\
$60 \mu \mathrm{mol} \mathrm{L}^{-1}$ & $38 \pm 11.73^{*}$ & $34 \pm 8.15^{*}$ & $39.8 \pm 10.21^{*}$ \\
Cisplatin (DDP) & & & \\
$20 \mu \mathrm{mol} \mathrm{L}^{-1}$ & &
\end{tabular}

$N=5 .{ }^{*} p<0.05,{ }^{* *} p<0.01,{ }^{* * *} p<0.001$ vs. control group.

between malignant tumor growth-related proteins, thereby enhancing the infiltration and metastatic ability of malignant tumors (24).

In this regard, to further investigate the effect of [Cu(PMPP-SAL)(EtOH)] on angiogenesis, we examined its potential regulatory effect on the expression of angiogenic proteins CD34, VEGF, and bFGF. The MVD values in the drug treatment group were significantly lower than those in the DMSO control group $(p<0.001)$ (Table II).

Immunohistochemical results also showed that the cell densities of VEGF and bFGF protein in untreated tumor-bearing mice were highly elevated, whereas these two indexes were also decreased significantly in tumor-bearing mice received [Cu(PMPP-SAL)(EtOH)] treatment at three doses $\left(20,40\right.$ and $\left.60 \mu \mathrm{mol} \mathrm{L}^{-1}\right)$ with lighter staining when compared to the negative control (Fig. 8), the $40,60 \mu \mathrm{mol} \mathrm{L}^{-1}$ dose groups demonstrated significantly lower expression of VEGF and bFGF than the control group (Table II) $(p<0.01)$, which suggests that higher concentrations of [Cu(PMPP-SAL $)(\mathrm{EtOH})]$ could inhibit the formation of tumor microvessels by inhibiting the expression of CD34, VEGF, and bFGF, leading to tumor growth inhibition through tumor cell apoptosis.

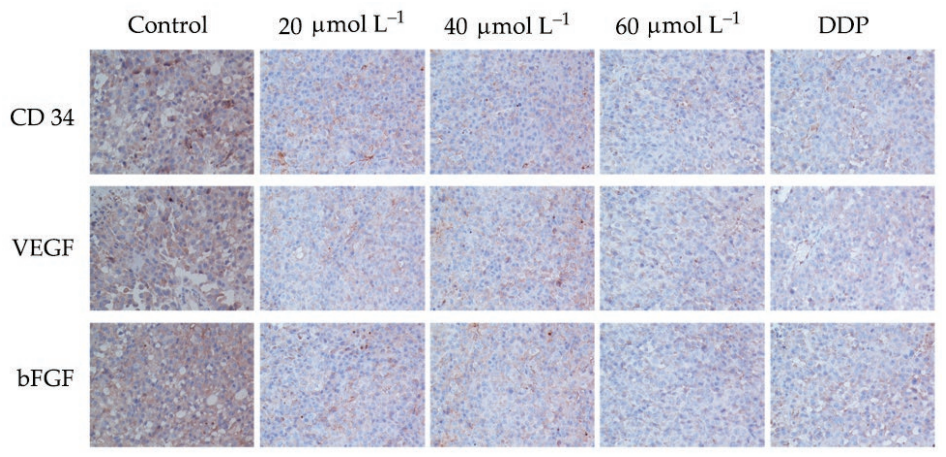

Fig. 8. Immunohistochemical analysis of CD34, VEGF, and bFGF in tumor tissues. The tumor issues derived from $\mathrm{C} 57 \mathrm{BL} / 6 \mathrm{~J}$ mice were treated with indicated concentrations of [Cu(PMPP-SAL)(EtOH)], positive control group (DDP), and control group (DMSO). The distribution of CD34, VEGF, and bFGF on the whole pathological tissue section was observed under a microscope at $200 \times$ magnification. 
a)

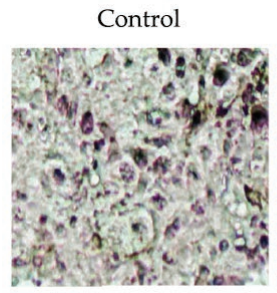

$60 \mu \mathrm{mol} \mathrm{L}^{-1}$

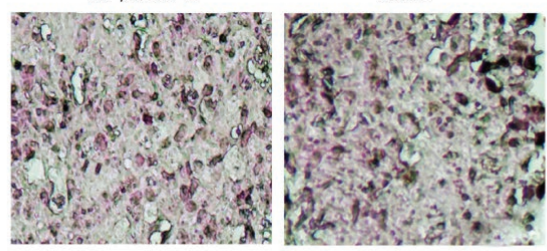

b)

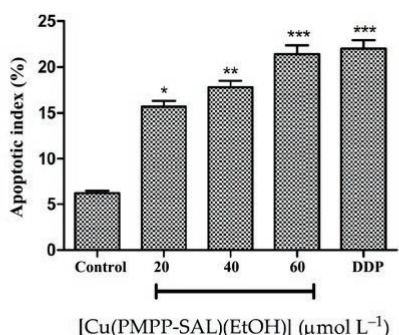

Cu(PMPP-SAL)(EtOH)] $\left(\mu \mathrm{mol} \mathrm{L}^{-1}\right)$
$40 \mu \mathrm{mol} \mathrm{L}{ }^{-1}$

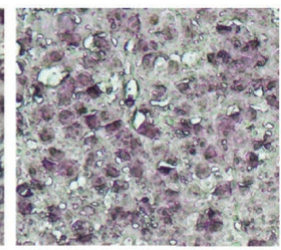

DDP

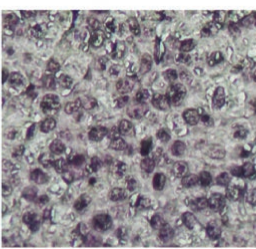

Fig. 9. a) Apoptosis detected using TUNEL assay in C57 BL/6J mice tumor tissues treated with indicated concentration of [Cu(PMPP-SAL)(EtOH)], positive control group (DDP), and control group (DMSO). TUNEL-positive nuclei, a pyknotic nucleus with indigo granules, were visualized and analyzed under a microscope at 200× magnification; b) The apoptosis index in C57 BL/6J mice tumor tissues. Data are presented as mean $\pm \mathrm{SD}(n=5) .{ }^{*} p<0.05,{ }^{* *} p<0.01,{ }^{* * *} p<0.001 v s$. control group (DMSO).

\section{$[C u(P M P P-S A L)(E t O H)]$ increased the number of apoptotic cells in vivo}

A small number of apoptotic cells were present in the tumors of the untreated control group; however, a large number of bluish violet apoptosis was detected in tumors treated with the indicated concentrations of [Cu(PMPP-SAL)(EtOH)] (Fig. 9a). Moreover, [Cu(PMPP$\mathrm{SAL})(\mathrm{EtOH})$ ] dose-dependently increased the values of AI $(p<0.05$ and $p<0.01)$ (Fig. 9b). These results suggested that $[\mathrm{Cu}(\mathrm{PMPP}-\mathrm{SAL})(\mathrm{EtOH})]$ suppresses tumor growth of B16 through the induction of apoptosis in vivo. These results are in accordance with those reported by Hua Yao et al (25).

\section{CONCLUSIONS}

In conclusion, the present study validated that [Cu(PMPP-SAL)(EtOH)] had indicated a good inhibitory effect on murine melanoma in vitro and in vivo. The down-regulation of 
CD34, VEGF, and bFGF protein expression in mice could inhibit tumor microangiogenesis and ultimately lead to tumor growth inhibition in vivo. Tumor-bearing mice demonstrated no serious adverse reactions to $[\mathrm{Cu}(\mathrm{PMPP}-\mathrm{SAL})(\mathrm{EtOH})]$ treatment, indicating the potential of this complex in melanoma treatment. However, melanoma is characterized by high drug resistance and high risk for recurrence, and hence it is difficult to obtain a superior therapeutic effect only through monotherapy or a single-agent treatment. Therefore, further studies need to be designed to investigate the underlying mechanism of apoptosis and combine $[\mathrm{Cu}(\mathrm{PMPP}-\mathrm{SAL})(\mathrm{EtOH})]$ with other chemotherapeutic drugs to enhance their therapeutic effect on melanoma tumors.

Acknowledgments. - This work was financially supported by the grant from the Natural Science Fund of Xinjiang Uygur Autonomous (No. 2013211A018), National Natural Science Foundation of China (No. 21361025), and Natural Science Fund for Distinguished Young Scholars of Xinjiang Uygur Autonomous (No. 2013711008). We also acknowledge Jianhua Yang who is contributed to the writing of the manuscript (Texas Children's Cancer Center, Department of Pediatrics, Dan L. Duncan Cancer Center, Baylor College of Medicine, Houston, Texas, USA).

\section{REFERENCES}

1. C. Cerchia and A. Lavecchia, Small molecule drugs and targeted therapy for melanoma: Current strategies and future directions, Curr. Med. Chem. 24 (2017) 1-33; https://doi.org/10.2174/0929867324 666170414163937

2. T. Zhang, Y. R. Suryawanshi, H. M. Woyczesczyk and K. Essani, Targeting melanoma with cancerkilling viruses, Open. Virol. J. 11 (2017) 28-47; https://doi.org/10.2174/1874357901711010028

3. P. Diamantopoulos and H. Gogas, Melanoma immunotherapy dominates the field, Ann. Transl. Med. 4 (2016) 269; https://doi.org/10.21037/atm.2016.06.32

4. A. A. Tarhini and S. S. Agarwala, Cutaneous melanoma: available therapy for metastatic disease, Dermatol. Ther. 19 (2010) 19-25; https://doi.org/10.1111/j.1529-8019.2005.00052.x

5. P. C. Bruijnincx and P. J. Sadler, New trends for metal complexes with anticancer activity, Curr. Opin. Chem. Biol. 12 (2008) 197-206; https://doi.org/10.1016/j.cbpa.2007.11.013

6. Y. Jung and S. J. Lippard, Direct cellular responses to platinum-induced DNA damage, Chem. Rev. 107 (2010) 1387-407; https://doi.org/10.1002/chin.200731270

7. M. S. Soengas and S. W. Lowe, Apoptosis and melanoma chemoresistance, Oncogene 22 (2003) 3138 3151; https://doi.org/ 10.1038/sj.onc.1206454

8. I. E. León, V. Porro, S. Astrada, M. G. Egusquiza, C. I. Cabello, M. Bollati-Fogolin and S. B. Etcheverry, Polyoxometalates as antitumor agents: Bioactivity of a new polyoxometalate with copper on a human osteosarcoma model, Chem. Biol. Interact. 222 (2014) 87-96; https://doi.org/ 10.1016/j. cbi.2014.10.012

9. J. Zhao, S. Gou and F. Liu, Potent anticancer activity and possible low toxicity of platinum(II) complexes with functionalized 1,1-cyclobutanedicarboxylate as a leaving ligand, Chemistry 20 (2014) 15216-15225; https://doi.org/ 10.1002/chem.201404090

10. S. Iglesias, N. Alvarez, M. H. Torre, E. Kremer, J. Ellena, R. R. Ribeiro, R. P. Barroso, A. J. Costafilho, M. G. Kramer and G. Facchin, Synthesis, structural characterization and cytotoxic activity of ternary copper(II)-dipeptide-phenanthroline complexes. A step towards the development of new copper complexes for the treatment of cancer, J. Inorg. Biochem. 139 (2014) 117-123; https://doi.org/ 10.1016/j.jinorgbio.2014.06.007

11. J. Lv, T. T. Liu, S. L. Cai, X. Wang, L. Liu and Y. M. Wang, Synthesis, structure and biological activity of cobalt (ii) and copper (ii) complexes of valine-derived Schiff bases, J. Inorg. Biochem. 100 (2006) 1888-1896; https://doi.org/ 10.1016/j.jinorgbio.2006.07.014 
12. V. M. Leovac, G. A. Bogdanović, L. S. Jovanović, L. Joksović, V. Marković, M. D. Joksović, S. M. Denčić, A. Isaković, I. Marković and F. W. Heinemann, Synthesis, characterization and antitumor activity of polymeric copper(II) complexes with thiosemicarbazones of 3-methyl-5-oxo-1-phenyl-3-pyrazolin-4-carboxaldehyde and 5-oxo-3-phenyl-3-pyrazolin-4-carboxaldehyde, J. Inorg. Biochem. 105 (2011) 1413-1421; https://doi.org/10.1016/j.jinorgbio.2011.07.021

13. X. Q. Zhou, Y. Li, D. Y. Zhang, Y. Nie, Z. J. Li, W. Gu, X. Liu, J. L. Tian and S. P. Yan, Copper complexes based on chiral Schiff-base ligands: DNA/BSA binding ability, DNA cleavage activity, cytotoxicity and mechanism of apoptosis, Eur. J. Med. Chem. 114 (2016) 244-256; https://doi.org/ 10.1016/j. ejmech.2016.02.055

14. X. H. Wang, D. Z. Jia, Y. J. Liang, S. L. Yan, Y. Ding, L. M. Chen, Z. Shi, M. S. Zeng, G. F. Liu and L. W. Fu, Lgf-YL-9 induces apoptosis in human epidermoid carcinoma KB cells and multidrug resistant KBv200 cells via reactive oxygen species-independent mitochondrial pathway, Cancer. Lett. 249 (2007) 256-270; https://doi.org/ 10.1016/j.canlet.2006.09.008

15. C. Kou, J. Zhao, Y. Li, G. Xu and S. Sun, Acute toxicity test of different doses of copper complex of pyrazolone derivatives in mice, Chin. Hosp. Pharm. J. 36 (2016) 821-825 (In Chinese).

16. G. C. Xu, L. Zhang, L. Liu, G. F. Liu and D. Z. Jia, Syntheses, characterization and crystal structures of mixed-ligand $\mathrm{Cu}(\mathrm{II}), \mathrm{Ni}(\mathrm{II})$ and $\mathrm{Mn}(\mathrm{II})$ complexes of (1-phenyl-3-methyl-4-propenylidene-5-pyrazolone)-salicylidene hydrazide containing ethanol or pyridine as a co-ligand, Polyhedron 27 (2008) 12-24; https://doi.org/ 10.1016/j.poly.2007.08.045

17. J. Zhao, L. Zhang, J. Li, T. Wu, M. Wang, G. Xu, F. Zhang, L. Liu, J. Yang and S. Sun, A novel pyrazolone-based derivative induces apoptosis in human esophageal cells via reactive oxygen species (ROS) generation and caspase-dependent mitochondria-mediated pathway, Chem. Biol. Interact. 231 (2015) 1-9; https://doi.org/ 10.1016/j.cbi.2015.02.004

18. Q. L. Wu, X. P. Wu, Y. J. Liang, L. M. Chen, Y. Ding and L. W. Fu, P-glycoprotein is not involved in pathway of anti-Fas/Fas-induced apoptosis in KBv200 cells, World. J. Gastroenterol. 11 (2005) 3544; https://doi.org/ 10.3748/wjg.v11.i23.3544

19. C. Chang, T. Wu, M. Wang, G. Xu and S. Sun, Antitumor effect of cadmium(II) complex of pyrazolone derivatives on melanoma B16 cells in vitro and in vivo, Chin. J. Pharmacol. Toxicol. 31 (2017) 405-413 (In Chinese).

20. G. Resta, G. Anania, F. Messina, D. D. Tullio, G. Ferrocci, F. Zanzi, D. Pellegrini, R. Stano, G. Cavallesco, G. Azzena and S. Occhionorelli, Jejuno-jejunal invagination due to intestinal melanoma, World. J. Gastroenterol. 13 (2007) 310; https://doi.org/ 10.3748/wjg.v13.i2.310

21. A. Dayton, K. Selvendiran, S. Meduru, M. Khan, M. L. Kuppusamy, S. Naidu, T. Ka'lai, K. Hideg and P. Kuppusamy, Amelioration of doxorubicin-induced cardiotoxicity by an anticancer-antioxidant dual-function complex, J. Pharmacol. Exp. Ther. 339 (2011) 350-357; https://doi.org/ 10.1124/ jpet.111.183681

22. H. Yang, D. Chen, Q. C. Cui, X. Yuan and Q. P. Dou, Celastrol, a triterpene extracted from the chinese "thunder of god vine," is a potent proteasome inhibitor and suppresses human prostate cancer growth in nude mice, Cancer. Res. 66 (2006) 4758; https://doi.org/ 10.1158/0008-5472.can-05-4529

23. W. Jiang, J. Cao, B. Pan and Y. Yu, Clinical significance of serum vascular endothelial growth factor and b-fibroblast growth factor before and after chemotherapy in patients with small cell lung cancer, Chin. J. Clin. Oncol. 40 (2013) 638-642; https://doi.org/ 10.3969/j.issn.1000-8179.2013.11.006

24. S. Imura, H. Miyake, K. Izumi, S. Tashiro and H. Uehara, Correlation of vascular endothelial cell proliferation with microvessel density and expression of vascular endothelial growth factor and basic fibroblast growth factor in hepatocellular carcinoma, J. Med. Invest. 51 (2004) 202; https://doi. org/ 10.2152/jmi.51.202

25. H. Yao, P. Cui, D. Xu, Y. Liu, Q. Tian and F. Zhang, A water-soluble polysaccharide from the roots of Polygala tenuifolia suppresses ovarian tumor growth and angiogenesis in vivo, Int. J. Biol. Macromol. 107 (2018) 713-718; https://doi.org/ 10.1016/j.ijbiomac.2017.09.043 